\title{
A PRÁTICA DO FUTEBOL AMADOR NA CIDADE DE IBIRITÉ-MG SOBRE A TEORIA DO LAZER SÉRIO DE ROBERT STEBBINS
}

Recebido em: 29/02/2020

Aprovado em: 01/07/2020

Licença:@) (1) @

\author{
Sheylazarth Presciliana Ribeiro ${ }^{1}$ \\ Erick Henrique dos Santos ${ }^{2}$ \\ Universidade Estadual de Minas Gerais (UEMG) \\ Ibirité - MG - Brasil
}

RESUMO: Esse artigo investiga as práticas do futebol amador na cidade de Ibirité/ MG e a perspectivas do lazer sério, de acordo com as teorias do autor Robert Stebbins. Na cidade de Ibirité - MG, o futebol amador é representado pelas escolas de futebol das categorias de base, pelas equipes amadoras que disputam os campeonatos, ligas e copas da região, sendo a Divisão Especial de Ibirité. O lazer sério é composto por seis características que a definem, são elas: perseverança; carreira; esforço; benefícios duráveis; ethos único; e identificação. Como metodologia, utilizamos entrevistas semiestruturadas com um jogador de cada time da Divisão especial da cidade, somando 20 entrevistas. Estas foram transcritas e interpretados, fazendo correlações com os critérios estabelecidos por Robert A. Stebbins sobre a Perspectiva do lazer sério, e verificar se o futebol amador se encaixa neste contexto. Sobre a identificação do futebol amador na cidade de Ibirité - MG, concluímos que tal prática não pode ser inserida com evidência nas Perspectivas do lazer sério, segundo os relatos obtidos nas entrevistas.

PALAVRAS-CHAVE: Futebol. Lazer Sério. Esportes.

\section{THE AMATEUR SOCCER IN IBIRITÉ CITY ON THE PERSPECTIVE OF SERIOUS LEISURE THEORY BY ROBERT STEBBINS}

ABSTRACT: This article investigates the practices of amateur soccer in Ibirite city (Minas Gerais - Brazil) and the serious leisure theory by the author Robert Stebbins. The amateur soccer in Ibirite is represented by the schools' soccer, by the amateur teams that compete in the championships, leagues and cups of the region. Serious leisure theory consists of six characteristics, they are: perseverance; career; effort; lasting benefits; unique ethos; and identification. As methodology we used semi-structured interviews with 1 player from each team of Ibirité special division (20 interviews). These were transcribed and interpreted, making correlations with the criteria established by serious leisure theory, and checking if amateur soccer in this context can be frame in the theory.

\footnotetext{
${ }^{1}$ Professora do Departamento de Ciências do Movimento Humano - DCMH da UEMG/Ibirité. Vicecoordenadora do grupo de estudos Ciranda da UEMG e participante dos grupos de estudos GESPEL e Oricolé da UFMG. Formadora do Programa Esporte e lazer da Cidade (2011 - 2019) e Coordenadora do Curso de Ed. Física da UEMG/Ibirité (2019 - atual). Direção da ADUEMG - Sindicato da UEMG (20182020).

${ }^{2}$ Licenciado em Educação Física pela UEMG.
} 
The amateur soccer in the Ibirité city cannot be inserted with evidence in the perspectives of serious leisure.

KEYWORDS: Soccer. Serious Leisure. Sports.

\section{Introdução}

Este artigo é resultado de uma pesquisa realizada na Universidade do Estado de Minas Gerais no ano de 2018, e que se apoia em dois eixos de estudo, o primeiro sobre a prática do futebol amador e o segundo sobre a perspectiva da teoria do lazer sério. Os dois temas têm definições que os regem sobre uma diversidade de contextos, em específico os recreativos e esportivos, e que podem ou não serem vivenciadas no mesmo contexto. Nesse trabalho buscamos verificar se a prática do futebol amador pode ser reconhecida como lazer sério.

Sendo assim, investigamos o futebol amador praticado na cidade de Ibirité - MG, procurando entender se essa atividade esportiva pode ou não ser pensada como uma prática da teoria do lazer sério, partindo dos estudos feitos pelo autor americano Robert A. Stebbins. Destacamos de início, que a cidade de Ibirité/MG apresenta realidade social e cultural diferente da realidade do autor Robert Stebbins, e assim de sua teoria. Essa experiência se justifica porque entendemos que submeter teorias sociológicas em contextos distintos tem potencial de explicação causal das teses propostas pelo autor, somando elementos teóricos ao lazer sério.

O interesse sobre o assunto partiu da vivência do futebol amador na cidade de Ibirité e da percepção de seriedade imposta pelos participantes. Citamos a rotina encontrada na preparação física e técnica dos jogadores para as disputas dos jogos, as organizações dos campeonatos tendo como inspiração a forma do alto rendimento no futebol. O futebol amador ocupa uma posição de relevância em nossa sociedade e nas 
vidas de seus participantes. Tal atividade envolve vários aspectos que nos fazem atribuir a seriedade aos seus praticantes.

A Divisão Especial de Futebol Amador de Ibirité é um evento relevante na cidade de Ibirité - MG. Essa informação foi ratificada em estudos e observações feitas anteriormente em uma pesquisa realizada na disciplina de Sociologia das Práticas Esportivas do curso de Licenciatura em Educação Física, da Universidade do Estado de Minas Gerais. O objetivo daquela pesquisa era verificar a atratividade do futebol amador na cidade de Ibirité - MG. Tal relevância atribuída pelos participantes a essa prática esportiva, instigou a prosseguir nos estudos sobre futebol amador.

Oliveira e Doll (2017) estabeleceram relações das práticas de corrida de rua e o fim da carreira de seus praticantes nesta modalidade. Os pesquisadores aplicaram questionários e entenderam que a prática de corrida de rua e o fim da carreira apresentam elementos que se enquadram na teoria do lazer sério. Inspirados nesse estudo, o objetivo central da pesquisa é verificar se a prática do futebol amador pode ser entendida como uma atividade das Perspectivas do lazer sério, levando em consideração as teorias de Robert A. Stebbins.

Para alcançarmos este objetivo, buscaremos: entender a prática do futebol amador e suas distinções do futebol profissional; descrever essa modalidade esportiva na cidade de Ibirité; conhecer bibliograficamente o autor Robert A. Stebbins e sua teoria do lazer sério; e identificar se há aspectos que possam caracterizar o futebol amador como uma atividade de lazer sério segundo os entrevistados.

A pesquisa foi realizada na Divisão Especial de Ibirité que é um campeonato de futebol amador executado no município e realizado pela Liga Desportiva do Município de Ibirité em convênio com a Secretaria de Esportes, Cultura e Lazer da cidade. A metodologia usada nesta pesquisa foi baseada em entrevistas semiestruturadas feitas com 
os jogadores de futebol amador que participam deste campeonato. Foram entrevistados 20 jogadores, sendo um representante de cada time, com o objetivo de diversificar os participantes desta entrevista e as representações de suas respectivas equipes.

O questionário foi composto por cinco perguntas: Por que praticar o futebol amador? Com objetivo de entender a justificativa em praticar esta modalidade; Há alguma preparação específica para esta prática? Essa suposta preparação é referente ao individual (jogador) e ao coletivo (equipe), buscando identificar e perceber a seriedade imposta pelo entrevistado e sua equipe em praticar essa atividade; Há quanto tempo pratica o futebol amador? Para verificar a legitimidade do participante dentro desta modalidade e perceber a importância do futebol amador para o entrevistado; Tem algum lucro com o futebol amador? Com objetivo de descobrir se o participante está presente dentro desta modalidade pelo lazer, ou se há algum lucro que o motiva estar ali; Tem pretensões dentro desta prática? O objetivo dessa pergunta é entender se o participante tem algum propósito a ser alcançado, sendo dentro dessa prática ou até mesmo em sua vida social, profissional e dentre outros. Tais perguntas foram extraídas da pesquisa; This is the end, my beautiful friend: lazer sério e o fim da carreira (OLIVEIRA e DOLL, 2017) e adaptadas para a elaboração deste estudo.

Os dados foram coletados no local do evento, sendo nos campos de futebol amador de Ibirité, as entrevistas foram gravadas, transcritas e interpretadas de acordo com os objetivos da pesquisa. Essa metodologia de pesquisa se dividiu em três etapas a primeira de preparação para coleta dos dados, quando foram elaborados os documentos necessários para realização da pesquisa, escolha da população a ser entrevistada e preparação dos objetos para a coleta. A segunda composta de uma análise de transcrição quando os dados foram descritos, classificados ou categorizados. E, por último a análise interpretativa quando os dados foram interpretados, fazendo associações com os critérios estabelecidos 
por Robert A. Stebbins sobre a perspectiva do lazer sério, e enfim verificar se o futebol amador se encaixa neste contexto.

\section{O Futebol, Futebol Amador e a Prática na Cidade de Ibirité-MG}

As práticas esportivas, em específico as que se denominam como esporte Moderno, surgiram em meados do século XIX como uma mercadoria das transformações sociais inglesas, fruto da Revolução Industrial e da organização do capitalismo (GIGLIO e RUBIO, 2013). Neste contexto destacamos o futebol como uma das principais modalidades que ganharam espaço na sociedade brasileira. As características do futebol são hereditárias de uma sociedade capitalista, prevalecendo as necessidades de mensuração de resultados, a competitividade e a seriedade imposta nesta modalidade esportiva (GIGLIO e RUBIO, 2013).

A disseminação do futebol na América Latina contou com os embates das classes dominantes e de grupos que lutavam pelo poder político das instituições esportivas, sendo o futebol usado como um lugar ou uma prática estratégica para a aquisição de bens financeiros, tendo em vista a atração pelo esporte no século XX (PEREIRA, 2000). Percebe-se que o futebol em países como Brasil e Argentina, bem como o Beisebol em Cuba, também foram peças de manobra utilizadas para a modernização das sociedades praticantes destas modalidades, auxiliando nas relações econômicas internacionais (ARCHETTI, 2003).

A introdução do futebol no Brasil se deu basicamente em dois tempos distintos; em primeiro momento, obedeceu-se a heterogeneidade da nossa expansão territorial, a distribuição do sistema urbano, as conexões com o exterior e o dinamismo de cada cidade, bem como as influências do Imperialismo Britânico. Em segundo momento as difusões no que diz respeito ao futebol foram inseridas nos grandes centros da sociedade brasileira 
A Prática do Futebol Amador na Cidade de Ibirité-MG sobre a Teoria do Lazer Sério... Sheylazarth Presciliana Ribeiro e Erick Henrique dos Santos

(GOERG, 2010). Subentende-se que o futebol foi inserido de diversas formas em cada espaço territorial e ele teve um papel relevante na formação da nossa sociedade, foi nesse esporte que o povo encontrou uma forma de se expressar (VELOZO; DAOLIO, 2017).

Inicialmente o futebol era uma prática restrita aos jovens componentes da elite republicana, seguindo o modismo oriundo da sociedade inglesa, porém esse paradoxo foi quebrado rapidamente, e logo o futebol se popularizou e passou a ser praticado em qualquer lugar e por qualquer pessoa no Brasil. Sua difusão e popularização permitiu que o mesmo se tornasse uma grande área esportiva da cultura nacional (GOERG, 2010). O futebol é um dos grandes eventos aglutinadores de pessoas, onde se cultuam diversas características e sentimentos englobados em nossa sociedade (SILVA; VOTRE, 2010), testificando sua autenticidade e influência na vida de seus praticantes e admiradores, fazendo do mesmo um dos principais, se não o principal esporte praticado em nosso país atualmente.

O futebol ocupa parte das nossas atenções no que diz respeito às práticas esportivas, chamado de esporte "bretão" tem o poder de despertar os mais diversos tipos de sentimentos em uma pessoa, seja-os bons ou ruins passageiros ou eternos, independentemente de seus apreciadores, esses sentimentos são comum em suas vidas (ALCÂNTARA, 2006). Percebemos essa afeição quando observamos os lugares destinados ao lazer, onde a atividade preferencialmente praticada é "jogar bola", destacamos também o papel da mídia nesse aspecto, pois a divulgação desse esporte sobrepõe as dos demais, tendo em vista os grandes campeonatos, clubes, jogadores e torcidas da atualidade, bem como os investimentos financeiros nesta modalidade esportiva. O futebol além de ser uma prática esportiva, tornou-se uma mercadoria que grandes empresas usam para faturarem lucros oriundos dessa exploração, tais interesses 
A Prática do Futebol Amador na Cidade de Ibirité-MG sobre a Teoria do Lazer Sério... Sheylazarth Presciliana Ribeiro e Erick Henrique dos Santos

econômicos contribuem para que o futebol seja difundido com mais eloquência em nosso território nacional (ALCÂNTARA, 2006).

O Brasil é conhecido como o "país do futebol” tendo em vista a aceitação deste esporte pelo povo brasileiro, pensado como um fenômeno esportivo dos dias atuais, o futebol tem características como as do carnaval e do samba, que fazem parte das expressões culturais da sociedade brasileira (VELOZO; DAOLIO, 2017).

Grande parte da reverência pelo futebol vem do público assistente, pois as ideologias dos clubes e times de futebol promovem fidelidade no acompanhamento dos jogos, e consequentemente uma cultura do futebol popularizada. Neste caso, podemos definir que um clube ou um time é uma instituição político-administrativa que tem a responsabilidade de organizar aquela representação futebolística (DAMO, 2008). Uma unidade futebolística pode ser caracterizada por duas equipes que buscam de forma assimétrica, o mesmo objetivo dentro de uma partida, cujo conflito é mediado por um objeto e um conjunto de regras (DAMO, 2008)

O futebol se divide em dois pólos:

Na contemporaneidade podem-se vislumbrar, de maneira geral, duas grandes territorialidades do futebol: a do futebol profissional, ou seja, aquela do futebol-espetáculo, dos grandes jogos transmitidos pela TV, dos estádios lotados, dos craques do mundo da bola, e a amadora, praticada a qualquer hora e lugar pelos amantes do futebol, os quais jogam pelo simples prazer proporcionado pelo lúdico do futebol, os peladeiros (GOERG, 2010, p. 5).

O autor compreende uma prática futebol que se manifesta de diferentes formas, entre essas, dois pilares se distinguem nas execuções de suas práticas. O futebol profissional e o futebol amador possuem intencionalidades inerentes que estão diretamente ligadas às características de seu processo de esportivização, como por exemplo, no futebol amador são enfatizadas as perspectivas do lazer como principal objetivo, já no futebol profissional observam-se as finalidades do trabalho, obtenção de resultados positivos, dedicação exclusiva e dentre outros (SILVA, 2011). 
A Prática do Futebol Amador na Cidade de Ibirité-MG sobre a Teoria do Lazer Sério... Sheylazarth Presciliana Ribeiro e Erick Henrique dos Santos

O futebol profissional é regido por um sistema internacional que engloba de modo hierárquico todas as práticas futebolísticas existentes atualmente, tal sistema é chamado de Fédération Internacionale de Football Association (FIFA). Nela estão inseridos todos os domínios deste esporte, não existe futebol profissional fora do sistema FIFA, e sobre as responsabilidades dela encontramos as confederações de futebol representantes de cada país, no caso do Brasil temos a Confederação Brasileira de Futebol (CBF), e em cada Estado brasileiro existem as federações de futebol, como em Minas Gerais temos a Federação Mineira de Futebol (FMF) (GIGLIO e RUBIO, 2013).

No futebol amador a organização e hierarquização é distinta da que encontramos no futebol profissional. Atualmente o futebol amador é conhecido como uma prática não profissional, realizadas em campos localizados nas "várzeas" ou em lugares possíveis a execução da atividade, e sua organização é predominantemente local (SILVA, 2011). As regras de um determinado esporte trazem diferenças entre as práticas profissionais e amadoras (PIMENTA, 2009). No futebol profissional, a legislação destinada às execuções das partidas é composta por regras que são fiscalizadas por uma equipe destinada a este trabalho. No futebol amador essas regras são adaptadas as questões locais para que a prática exista, pois regulamentações como as das dimensões do campo, que quase sempre não correspondem às mesmas dimensões de um campo de futebol profissional, inviabilizariam a prática.

No futebol profissional além de se fazer valer das regras impostas pela FIFA para a realização das partidas, existem alguns valores empregados dentro de campo e podemos destacar a disciplina técnica dos jogadores. Na visão dos times a equipe é vista como uma "máquina" e o jogador é uma "peça" componente desta máquina, sendo que a perfeita harmonia proporcionará o bom rendimento do time (FLORENZANO, 1998). Já no futebol amador, essa disciplina não é pré-requisito, pois é comum existirem jogadores 
que não obedecem às funções técnicas ou táticas de sua equipe, às vezes pela imperícia de não saber fazer, ou até mesmo pela desobediência nas execuções das funções.

Destacamos anteriormente que o futebol, em específico o profissional, se tornou um grande polo de fins lucrativos para empresas e ou instituições. Poucos jogadores adquirem o status de celebridade em pouco tempo, e atingem um alto poder aquisitivo oriundo da prática futebolística, normalmente essas características se tornam possíveis a partir de assinaturas dos contratos milionários dos grandes clubes da atualidade (GIGLIO e RUBIO, 2013). No cenário do futebol amador essas características se diferem, pois os investimentos nessa modalidade são mínimos. Os atletas amadores raramente recebem algum tipo de remuneração e ou contrato pelo esforço da atividade, os clubes e times não recebem investimentos de grandes empresas e ou instituições que possam viabilizar esta suposta remuneração. Sobretudo, as equipes amadoras que tentam seguir os mesmos padrões administrativos das equipes profissionais, normalmente são compostas por uma presidência, uma diretoria, comissão técnica e atletas, alguns até registrados em cartório. Os responsáveis pela organização se preocupam em montar times competitivos para as disputas dos campeonatos, e os investimentos são oriundos dos sócios e das doações por parte da torcida que tem afeição pelo time e seus integrantes, que na maioria das vezes são parentes ou amigos da comunidade (PIMENTA, 2009).

Geralmente os praticantes de futebol amador não são compelidos a exercer tal ocupação em busca de uma carreira profissional, fins lucrativos ou ambição pelos resultados positivos e que condizem pela dedicação exclusiva à atividade, pois os mesmos exercem na maioria das vezes, outros cargos profissionais. Os atletas desta natureza, normalmente praticam o futebol amador pela identificação com a prática, a manutenção da saúde, o preparo físico, a socialização entre os amigos, bem como aliviar o estresse 
psicológico do dia a dia. Tal prática amadora pode ser vista como um método terapêutico (GOERG, 2010).

Na cidade de Ibirité - MG, que conta com uma população de aproximadamente 171.932 habitantes (IBGE, 2014), e possui uma estrutura de políticas públicas de esporte e lazer reduzida. As duas ações da prefeitura permanentes são as aulas de zumba em praças e as escolinhas de futebol nos diferentes bairros da cidade.

O futebol amador na cidade é representado pelas escolas de futebol das categorias de base, podemos destacar a equipe do Boa Esperança Futebol Clube, time de maior relevância neste aspecto. Entre as equipes amadoras que disputam os campeonatos locais, regionais e estaduais, destacam-se a equipe do Torino Futebol e Lazer e a equipe do Valência Esporte Clube. Um campeonato que ocorre no município é a Divisão Especial de Ibirité (evento que abraçou esta pesquisa). Essas representações enriquecem a prática do futebol amador na cidade, conquistando vários adeptos para a modalidade na cidade de Ibirité - MG.

Sobre o contexto histórico que o futebol amador percorreu na cidade até os dias atuais, não temos relatos devido a inexistências de documentos comprobatórios sobre este feito, sendo assim, é necessário à realização de pesquisas apuradas com os precursores desta modalidade amadora na presente região.

A Liga Desportiva do Município de Ibirité promove anualmente em parceria com a Secretaria de Esportes, Cultura e Lazer da cidade, o campeonato de maior relevância do município. A Divisão Especial de Ibirité é composta por três divisões: $2^{a}$ Divisão que comporta os times iniciantes na liga e os times que não conseguem subir para as demais divisões; $1^{a}$ Divisão que é composta pelos times que buscam acesso a principal divisão da liga; e a Divisão Especial de Ibirité. Os jogos da Liga Desportiva do Município de Ibirité são acompanhados por uma equipe de arbitragem completa (juiz e bandeirinhas). 
Composta por vinte equipes e aproximadamente 400 jogadores, a Divisão Especial de Ibirité é o campeonato de maior relevância da cidade, se divide em duas chaves (A e B). As equipes disputam as partidas entre si, dentro de suas respectivas chaves, as oito primeiras equipes, levando em consideração as duas chaves, passam para as fases finais da competição, e as quatro últimas caem para a $1^{a}$ Divisão, e o time campeão tem acesso garantido na Copa Itatiaia de Futebol Amador, representando a cidade nessa competição nível estadual.

Os atletas que desejam participar da Liga Desportiva da cidade devem estar filiados a somente uma equipe, dentro daquela divisão específica pelo qual jogará, o jogador pode se filiar a outra equipe para as disputas das outras divisões. A liga organiza as diretrizes impostas na competição possibilitando que todo o evento aconteça, os jogos são prestigiados pela população local testificando a aceitação e afeição pelo futebol amador.

\section{O Lazer Sério do Autor Robert. A. Stebbins}

O termo "lazer" abrange várias definições que atualmente são estudadas e discutidas por autores (GOMES, 2014; MELO, 2010), principalmente no que diz respeito as suas generalidades. Lazer pode ser definido como uma atividade que não é praticada por meio da força ou da necessidade, inserida basicamente nos tempos livres do sujeito que a realiza em busca do prazer usando suas habilidades e ou recursos a que faz jus, ou estão dispostos sobre sua custódia (STEBBINS, 2012).

Sobre as discussões de lazer, podemos destacar o autor Robert. A Stebbins como um produtor de vários artigos e livros, ele é sociólogo e iniciou seus estudos sobre o lazer em 1973. Professor aposentado da Universidade de Calgary no Canadá se atém a explorar em específico, as atividades desenvolvidas pelos amadores, que em grande parte são os 
A Prática do Futebol Amador na Cidade de Ibirité-MG sobre a Teoria do Lazer Sério... Sheylazarth Presciliana Ribeiro e Erick Henrique dos Santos

músicos, artistas, jogadores de futebol e beisebol, mágicos, comediantes e astrônomos (STEBBINS, 2011). No ano de 2002, Stebbins passou a ser responsável por uma seção em Newsletter chamada de Leisure Reflection (Reflexões do lazer) que se encontra no periódico Leisure Studies Association (Associação de estudos do lazer) que trata de um centro científico sobre o lazer (OLIVEIRA; DOLL, 2012). Em 2010, Stebbins foi eleito membro sênior da World Leisure Academy (Academia Mundial de Lazer), concretizando a relevância dos seus estudos sobre este exaltado assunto (OLIVEIRA; DOLL, 2012).

O sociólogo desenvolveu o conceito do "lazer sério", que está inserido nas generalidades do lazer e comporta características descritas para essa especificidade. Tal conceito nasceu nos anos entre 1973 a 1976, quando Stebbins coletava alguns dados de um estudo sobre os atletas amadores e profissionais. No decorrer das entrevistas desta pesquisa, o autor percebeu que os jogadores amadores de beisebol se negaram a afirmar que suas práticas eram simplesmente uma forma de lazer, pois eles se dedicavam ao esporte buscando alcançar o alto rendimento, se empenhando ao máximo para o desenvolvimento de suas habilidades, com o intuito de obter resultados positivos. Logo suas práticas eram tratadas como "algo sério", e assim Stebbins foi induzido a mudar sua linha de raciocínio buscando entender o que os atletas amadores daquela prática esportiva estavam se referindo (STEBBINS, 2008).

O termo lazer sério foi escolhido por Stebbins por se aproximar das declarações daqueles atletas amadores, porque os conceitos que regiam tal tema até aquele momento se referiam ao lazer como "um tempo de fruição", se distinguindo da seriedade e comprometimento dos atletas entrevistados (OLIVEIRA; DOLL, 2012).

Stebbins define o lazer sério como:

[...] a prática sistemática de uma atividade por amadores, praticantes de hobby ou voluntários, considerada substancial, interessante e realizadora que em casos típicos, lança-lhes numa carreira (de lazer) centrada na aquisição e expressão de uma combinação de habilidades especiais, conhecimento e experiência (STEBBINS 2008, p.5, tradução de OLIVEIRA e DOLL 2012). 
O lazer sério é composto por basicamente seis características distintas, mas que correlacionam entre si, e que foram encontradas nos atletas amadores pesquisados pelo autor nas execuções de suas práticas, dentro desse contexto. A "perseverança" aparece em primeiro lugar, e faz alusão à necessidade de persistência de seus praticantes, mesmo em casos de fracassos, eles buscam de todas as formas os resultados positivos, não se contentando somente com a execução prática dentro do contexto esportivo. O sujeito pode seguir uma "carreira" na atividade pelo qual está inserido, sendo essa a segunda característica. O conceito de "carreira", embora seja entendida como uma definição geral de progressão no trabalho, dentro das perspectivas do lazer sério este termo está ligado à continuidade do praticante dentro das atividades amadoras pela qual está inserido, independentemente do momento vivido, sendo de sucesso ou fracasso. A terceira característica se define como o "esforço" encontrado no participante para que possa desenvolver seus conhecimentos, experiências e técnicas. A quarta característica que pode ser o resultado deste "esforço" encontrado na terceira característica, que são os "benefícios duráveis", estes abrangem a ordem emocional e social, propiciando ao sujeito um descanso compensador do estresse do dia a dia, bem como a socialização entre os seus amigos. Estas características ocorreram com frequência nos participantes de atividades amadoras. A quinta característica é conhecida como "ethos único", este engloba os valores manifestados pelos praticantes dentro do contexto da prática, que podem ser os objetivos, sentimentos, atitudes e dentre outros, e seguindo neste aspecto percebemos a sexta característica que é a "identificação" dentre os participantes do lazer sério, este conota o tempo de vivência do sujeito na atividade, bem como se refere e interpreta a prática amadora pela qual exerce (STEBBINS; ELKINGTON, 2014).

No lazer sério existe uma relação entre os custos e os lucros inseridos nas atividades, e segundo Stebbins essa relação se constitui em dois polos: os custos vêem 
A Prática do Futebol Amador na Cidade de Ibirité-MG sobre a Teoria do Lazer Sério... Sheylazarth Presciliana Ribeiro e Erick Henrique dos Santos

em sua generalidade das decepções e despontamentos dos participantes dentro da prática, que por vez faz parte, causando-lhe um custo psicológico não benéfico; e, por outro lado, os lucros podem ser as recompensas e ou premiações pessoais pelo bom desenvolvimento das habilidades e conhecimento inerentes ao sujeito, fazendo-lhe importante e indispensável dentro daquela atividade ou de um determinado grupo (STEBBINS, 2008).

A partir dessas características atribuídas ao lazer sério, Stebbins desenvolveu posteriormente outras duas formas de lazer, que são: o "lazer casual" e o "lazer baseado em projetos", e sobre essas três formas de lazer que o autor formulou e ratificou as teorias da "Perspectiva do Lazer Sério"; Sendo que a primeira forma de lazer (lazer sério) ganhou lugar de destaque dentro do contexto da perspectiva, sendo considerado como "carrochefe" da teoria e sendo usado como título da mesma (OLIVEIRA; DOLL, 2012).

Stebbins define o lazer casual como uma atividade imediata, de valor intrínseco, com satisfação relativamente curta e que não requer nenhum tipo de habilidade especial para ser aproveitada, podemos citar algumas atividades dessa natureza; viajar, ir aos cinemas, clubes e teatros e dentre outras (STEBBINS, 2008). As atividades do lazer casual produzem em seus participantes um relevante nível de "prazer" e "contentamento", bem como a manutenção das relações interpessoais, como a socialização. Outro aspecto a ser citado sobre o lazer casual é a possibilidade que ele oferta aos seus participantes de alcançarem o "bem-estar" executando tais atividades proeminentes ao termo citado (STEBBINS, 2008), tais características definem com propriedade o lazer casual.

O lazer baseado em projetos é definido como uma tarefa criativa, excepcional ou ocasional, que necessita de um planejamento, conhecimento e habilidade específica para que possa ser desenvolvida, mas que se difere do lazer sério, pois os participantes não almejam se desenvolver nesta tarefa ou nessas qualidades investidas na execução da prática (STEBBINS, 2008). Os projetos se dividem em dois aspectos; "projetos 
ocasionais" que são aqueles eventos que ocorrem de forma regular (semanalmente, mensalmente, anualmente), como as festas folclóricas, religiosas e de aniversário, nas quais seus integrantes desenvolvem habilidades para as formulações dos eventos e ou atividade, provocando uma imensa satisfação naquele momento. Os "projetos excepcionais", que acontecem excepcionalmente como alguns eventos artísticos e esportivos, o participante só objetiva cumprir a tarefa e nada a mais (STEBBINS, 2008). Esses tipos de projetos possuem a possibilidade de se tornarem rotineiros em alguns casos, especialmente quando os seus participantes sentem satisfação na realização e na criação dos mesmos, se tornando uma fórmula para os próximos acontecimentos eventuais. No lazer baseada em projetos há também o desenvolvimento das relações interpessoais, como no lazer casual, pois o projeto gira em torno de um mundo social envolvendo amigos, vizinhos, familiares e etc. (STEBBINS, 2008).

No lazer sério, as atividades em geral permitem que haja um senso de continuidade, promovendo o desenvolvimento dos participantes e consequentemente temos como fruto o crescimento pessoal daqueles que ali estão envolvidos. Os participantes que permanecem em suas atividades sérias acabam passando por alguns estágios, como o início, desenvolvimento, estabelecimento, manutenção e declínio, porém as diferenças entre esses estágios são imprecisos e imperceptíveis, assim como sugere o senso de continuidade, os participantes avançam de um estágio para o outro rapidamente, não demostrando aparentemente tal distinção (STEBBINS; ELKINGTON, 2014).

\section{Prática do Futebol Amador na Cidade de Ibirité-MG: A Perspectiva do Lazer Sério}

Seguindo nos objetivos deste estudo, investigamos se o futebol amador pode ser entendido como uma atividade do lazer sério na cidade de Ibirité/MG. Entre os motivos 
que levam os jogadores a praticar o futebol amador destacaram-se três: a prática como geradora de socialização; manutenção da saúde física e psicológica; e ocupação de tempo livre.

O motivo de socialização teve frequência nas respostas de doze atletas, assim, eles afirmaram que jogam o futebol amador pelo fato do divertimento e descontração que ali são vivenciadas para o cultivo de suas amizades, bem como a expansão de suas relações sociais, como disse um dos entrevistados da equipe do Ipê Esporte Clube: "Eu jogo pela diversão entre os meus amigos mesmo, conhecer pessoas novas". Associamos a ideia de vínculos humanos à promoção de ganhos sociais, pois entre pessoas que partilham mesma experiência pode-se aprender e ensinar alguns aspectos inerentes a formação humana, alcançando novos saberes que poderiam proporcionar desenvolvimento pessoal. Segundo Stebbins (2008) os praticantes do lazer sério, ao partilharem contextos, tendem a assemelharem-se uns aos outros caracterizando outra qualidade de sua teoria, a identificação.

O motivo socialização se aproxima da abordagem de Stebbins (2008) também pela característica de benefícios duráveis nas práticas. Para o autor, o lazer sério reúne ganhos de ordem emocional e social, os praticantes reconhecem a integração social, a melhoria da autoimagem.

O segundo motivo que surge nas respostas de seis atletas é a questão da manutenção da saúde física e psicológica que o futebol amador proporciona. Eles dizem que a prática pode impedir a inserção na vida sedentária e é um momento de alívio psicológico advindo do estresse do dia a dia. Assim afirmou um jogador da equipe do Real Marilândia Futebol Clube: "O futebol amador é uma forma de manter o condicionamento físico e aliviar o estresse do dia a dia". 
Alguns atletas relataram o alívio psicológico que encontram na prática do futebol amador, tendo em vista o estresse cotidiano. Esses argumentos se associam ao que Stebbins (2008) nomeia de benefícios duráveis no lazer sério, pois o relato mostra a ideia de compensação na prática do futebol amador em relação as demandas da vida do trabalhador de Ibirité.

O terceiro motivo aparente foi a prática do futebol amador como ocupação do tempo, afirmado por dois jogadores. Esse aspecto como causa motivacional para a prática foi pouco frequente. Essa resposta não se associa à nenhuma característica atribuída ao lazer sério.

Concluímos que, nas razões para praticar o futebol amador, encontramos duas respostas que se correlacionam com as características do lazer sério. Retomando as características dos "benefícios duráveis" de Robert Stebbins, que relaciona as atividades de lazer aos significados de usos pessoais, como questões sociais e emocionais. As falas ilustram essas características de socialização articulados à ideia de diversão. Segundo lugar em frequência de respostas, a ideia de "condicionamento físico" e "alívio do estresse cotidiano".

A preparação específica dos jogadores para a prática, com potencial de argumentos sobre a característica "esforço" da teoria de Stebbins (2008), mostrou que treze atletas não têm nenhum tipo de preparação para a prática, seis atletas responderam que se preparam pouco e somente um atleta se prepara de forma específica para a realização dos jogos de futebol amador. Uma das qualidades que definem o lazer sério é identificada como "esforço", percebe-se que esse quesito requer de seus participantes algum tipo de trabalho, treinamento ou capacitação específica para que possam desenvolver seus conhecimentos, técnicas e habilidades dentro daquela atividade 
exercida, logo os atletas que não se preparam ou se preparam pouco não se enquadram nas características do lazer sério.

Podemos destacar que a questão do trabalho semanal como um dos motivos pelo qual o jogador de futebol amador não se prepara especificamente para a execução dos jogos, como afirma o atleta que representa a equipe Associação Atlética Manchester: “Não! Não! Não há uma preparação específica para a prática do futebol amador, até mesmo pela questão do trabalho durante a semana, então chega nos fins de semana e a gente só quer jogar o futebol mesmo!" Segundo relatos, percebemos que alguns jogadores se preparam pouco, e até concordam que deveriam se preparar de forma específica para as disputas dos jogos, assim afirmou o representante da equipe Esporte Clube Torino: "Minha preparação são corridinhas leves durante a semana, nada em específico, mas sei que seria importante sim, ter uma preparação exclusiva para os jogos do campeonato”. Só encontramos essa preparação específica nas respostas de dois jogadores, sendo que este número representa somente $10 \%$ da população entrevistada, pouco frequente para concretizar o futebol amador como um lazer sério.

A “identificação" é a sexta qualidade que compõe as características do lazer sério, nesse aspecto, um dos requisitos que o participante precisa obter para se identificar com a prática, é ter um tempo de vivência consideravelmente importante dentro da mesma. Sendo assim, no terceiro questionamento buscamos verificar a quanto tempo os jogadores praticavam futebol amador. Aqueles que responderam estar inseridos neste contexto por um tempo superior a três anos foram considerados próximos a categoria do lazer sério, pois é um período relativamente suficiente para que o sujeito passe pelos estágios de início, desenvolvimento, estabelecimento, manutenção e declínio (STEBBINS; ELKINGTON, 2014). 
Levando em consideração esse parâmetro observamos que onze jogadores correspondem a esse quesito obtendo um tempo de vivência relevante dentro do futebol amador. Nove jogadores não podem corresponder, pois ainda não atingiram este tempo e estágios pré-determinados.

Tomando como referência uma frequência superior a 50\% para generalizar as aproximações da prática do futebol amador em Ibirité com a teoria do lazer sério, no quesito ethos único existe aproximação, pois $55 \%$ da população entrevistada é englobada na característica da "identificação". Contudo, os valores que diferenciam essas características do tempo de prática no futebol amador são bem próximos, o que nos leva a outros questionamentos sobre o tempo de prática e a vida dos jogadores de futebol amador em Ibirité. Seria uma prática que consegue receber velhos do município?

Os lucros que os participantes podem receber em troca do bom desenvolvimento de suas habilidades, conhecimentos ou técnicas, e que o torna indispensável naquela atividade é outro ponto de análise. Os relatos afirmam que não recebem nenhum tipo de lucro e ou premiações pela execução desta atividade esportiva, e pelo contrário, às vezes, são acarretados de gastos oriundos da prática, como disse o jogador da equipe Bola de Ouro: "Eu não tenho lucro jogando bola, e às vezes até ajudamos financeiramente nas lavagens dos uniformes ou comprando algum tipo de material”. Neste caso, percebemos que o jogador está inserido no futebol amador por outras razões, pois não há recompensa financeira.

No relato do jogador representante da equipe Real Esporte Clube existe uma diversificação de resposta: "Não! Eu nunca recebi e nem recebo nada para jogar, mas conheço alguns que recebem". Levando em consideração a afirmação, e a partir das observações e vivências dentro dessa modalidade esportiva, podemos afirmar que há 
jogadores que são pagos e que algumas equipes investem no pagamento com o objetivo de conquistar os campeonatos, ligas e copas, dentro e fora da região.

Neste questionamento, os relatos dos entrevistados não se encaixam nas características do lazer sério, pois todos os jogadores entrevistados não relacionam a prática com a questão do lucro oriundo da atividade que poderia acarretar na ideia de “carreira" no lazer.

As pretensões com o futebol amador dos jogadores entrevistados podem se relacionar com duas qualidades do lazer sério, sendo elas a "perseverança" que é quando o atleta persiste em praticar a atividade pelo qual está inserido, pois ela se tornou substancial em sua vida, e a qualidade do "ethos único". Este último é objetivo e sentimento que o atleta vive dentro da prática, sendo algo interessante e realizador para si, e, se existem pretensões para o futebol amador, consequentemente ele terá tais qualidades expostas. As respostas seguiram em um mesmo sentido, todos os entrevistados afirmam que não tem pretensões jogando o futebol amador e que só jogam por diversão. Afirmações desta natureza entram em contradição com as qualidades do "ethos único", pois os jogadores não obtêm sentimentos e objetivos na execução da prática, como nos dizeres do jogador da equipe do $\mathrm{ABC}$ Esporte Clube: "Então, eu não tenho nenhuma pretensão jogando bola, aqui é só por prazer mesmo".

Em algumas respostas, observamos que apesar de não terem nenhum objetivo específico dentro da atividade, os jogadores querem conquistar os campeonatos da cidade, todavia sabem que esse fato não é possível, e que não dão tanta ênfase neste quesito, como disse o jogador da equipe Morada da Serra Esporte Clube: Não tenho certa pretensão jogando bola, o objetivo é tentar ganhar o campeonato mesmo, mas se não der certo, fazer o que! Essa resposta entra em contradição com as características da "perseverança". Nela o sujeito busca os resultados positivos a qualquer custo. $\mathrm{O}$ simples objetivo de querer 
conquistar os campeonatos, não pode ser relacionado com as qualidades do lazer sério, pois é algo comum nos participantes do futebol amador, e consequentemente não faz da atividade algo substancial e realizador na vida dos mesmos.

Nos parece que substancial nesse caso é o prazer de estar lá, jogar por jogar e encontrar as pessoas, demonstrando que a atividade é relevante para a comunidade, mesmo não se aproximando da teoria do lazer sério. Sabemos que a teoria do lazer sério é composta por três especificidades (lazer sério, lazer casual e o lazer baseado em projetos), porém nessa pesquisa, os dados obtidos foram comparados somente com as características do lazer sério. Refutamos a ideia de que o futebol amador apresentaria nessa especificidade o contexto que Robert A. Stebbins a desenvolveu.

Olhando especificamente para o que poderia ser o mundo social do lazer sério, o futebol amador teria uma estrutura de investimentos que mantém a permanência dos praticantes, e aproximaria da ideia de carreira. A carreira teria alternativas de manutenção do vínculo com as práticas de lazer, através da atuação em diferentes papéis, como quando o sujeito deixa a atividade principal e, portanto, não é mais coadjuvante e passa a assumir outro papel na estrutura do futebol amador (OLIVEIRA; DOLL, 2017).

\section{Considerações Finais}

Em nossa análise, identificamos processos distintos que contextualizam a inserção jogadores de futebol amador, como as diferenciações no que diz respeito as regras da FIFA e as condições locais, investimentos financeiros na prática e disciplina técnica e tática entre os jogadores de futebol amador e futebol profissional. Na cidade de Ibirité MG, o futebol amador é representado pelas escolas de futebol das categorias de base, pelas equipes amadoras que disputam os campeonatos, ligas e copas da região, sendo a Divisão Especial de Ibirité o campeonato de maior relevância da cidade. Este é 
organizado pela Liga Desportiva do Município de Ibirité em convênio com a Secretaria de Esportes, Cultura e Lazer.

O futebol amador apresentou à primeira vista elementos que se aproximavam, ou buscam se aproximar do futebol profissional, e essa aproximação se apresentou principalmente na identificação de elementos que estão nas bases do futebol e nos ajudam a entender um pouco mais sobre os jogadores do futebol amador. Como uma forma de reforçar nossa argumentação, acrescentamos dados que obtivemos não por participar especificamente de um time da cidade de Ibirité, mas por estarmos inseridos em uma sociedade que comporta um mercado que lucra e produz desejos com o futebol, seja como torcedores, jogadores amadores ou escolinhas.

Os dados apresentados permitem uma relativa generalização de características no grupo de jogadores de futebol amador na cidade de Ibirité/MG, e não devem servir para caracterizar o futebol amador da região centro de Minas Gerais. Contudo, elementos podem parecer peculiares de um grupo e observados em níveis mais amplos dentro de quadros similares.

Sobre a identificação do futebol amador na cidade de Ibirité - MG, concluímos que tal prática não pode ser inserida com evidência nas perspectivas do lazer sério, segundo os relatos obtidos nas entrevistas. Percebemos que os jogadores de futebol amador dessa região praticam essa modalidade pelo fato da socialização, ocupação de tempo, manutenção da saúde física e psicológica. A maioria dos entrevistados afirmam que não se preparam, ou se preparam pouco para a prática, não recebem nenhum tipo de provento financeiro para a execução da atividade e não têm pretensões dentro do futebol amador. Encontramos algumas características lidas sob a ótica da teoria do lazer sério, contudo elas são menos frequentes, o que nos permite afirmar que o futebol amador da 
cidade de Ibirité - MG não pode ser entendido com propriedade como uma prática do lazer sério.

Por fim, a cidade de Ibirité possui problemas sociais e falta de políticas públicas de lazer descentralizadas, contexto distante do berço do lazer sério. Essa pesquisa oferece características do futebol amador local que é uma vivência completamente singular, envolvente e capaz de representar uma dimensão que representa a própria vida dos envolvidos com os times e com essa manifestação cultural.

\section{REFERÊNCIAS}

ALCÂNTARA, H. A magia do futebol. Estudos avançados, São Paulo, v. 20, n. 57, p. 297 - 313, maio/ago. 2006.

ARCHETTI, E. Masculinidades: fútbol, tango y polo enla Argentina. Buenos Aires: Antropofagia, 2003.

DAMO, A. S. Dom, amor e dinheiro no futebol de espetáculo. Revista Brasileira de Ciências Sociais, v. 23, n. 66, p. 139-150, 2008.

FLORENZANO, José Paulo. Afonsinho e Edmundo: a rebeldia no futebol brasileiro. Musa Editora, 1998.

GIGLIO, S. S; RUBIO, K. Futebol profissional: o mercado e as práticas de liberdade. Revista Brasileira de Educação Física e Esportes. São Paulo, p. 387-400, julho 2013.

GOERG, M. Futebol na várzea: uma investigação nos valores presentes no cotidiano da prática. 2010. 25 f; Trabalho de conclusão de curso - Universidade Federal do Rio Grande do Sul, 2010.

GOMES, Christianne Luce. Lazer: necessidade humana e dimensão da cultura. Revista Brasileira de Estudos do Lazer, v. 1, n. 1, p. 3-20, 2014.

MELO, Victor Andrade de. Esporte e lazer: conceitos. Rio de Janeiro: Apicuri, 2010.

OLIVEIRA, S. N; DOLL, J. O serious leisure de Robert a. Stebbins. Licere, v. 17, n. 1, p. 1-22, 2014. DOI: doi.org/10.35699/1981-3171.2014.631

2012. Serious Leisure. Movimento (ESEFID/UFRGS), v.18, n.1, p. 325-338, 'This is The End, My Beautiful Friend!': lazer sério e o fim da carreira. Educação \& Realidade, v. 42, n.1, p. 215-236, 2017. 
PEREIRA, M. A. L. Footballmania: uma história sobre o futebol no Rio de Janeiro, 1902 a 1938. Rio de Janeiro: Nova Fronteira, 2000.

PIMENTA, R. Futebol amador na cidade e no sertão: o jogo das regras e a dinâmica figuracional elisiana. SIMPÓSIO INTERNACIONAL PROCESSO CIVILIZADOR. $v$. 12, p. 1-13, 2009.

SILVA, C. A. F. da; VOTRE, S. J. Futebol, imaginário e mídia: as metáforas da discriminação no futebol brasileiro. Corpus et Scientia, v. 6, n. 1, p. 65-80, 2010. Disponível

em:

http://apl.unisuam.edu.br/revistas/index.php/corpusetscientia/article/view/158/135.

Acesso em: fev. 2020.

SILVA, J. L. F. Futebol: amadorismo em tempos de profissionalismo. Fortaleza. Revista de Ciências Sociais, v. 42, p. 64-76, 2011.

STEBBINS, R. A.; ELKINGTON, S. The serious leisure Perspective: an introduction. London: Routledge, 2014.

Personal Memoirs, Project-Based Leisure and Therapeutic Recreation for Seniors. Leisure Studies Association Newsletter, Bolton, 2011.

Serious Leisure: a perspective for our time. New Jersey: Transaction, 2008.

The Idea of Leisure: first principles.New Brunswick: Transaction, 2012.

VELOZO, E. L; DAOLIO, J. Futebol, mundialização e identidades: notas a partir da Eurocopa de 2008. Publicatio UEPG. Ciências Sociais Aplicadas, v. 25, n.2, p. 257-257, 2017.

\section{Endereço do(a) Autor(a):}

Sheylazarth Presciliana Ribeiro

Alameda do Contorno, 1518, condomínio Quintas da Lagoa

Sarzedo - MG - 32.450-900

Endereço Eletrônico: sheylazarth.ribeiro@uemg.br

Erick Henrique dos Santos

Rua Águas da Prata, 145, bairro Jatobá

Belo Horizonte - MG - 30.692-450

Endereço Eletrônico: erick_al37@hotmail.com 